\title{
The Abortion Web Ecosystem: Cross-Sectional Analysis of Trustworthiness and Bias
}

Leo Han ${ }^{1}$, MD, MPH; Emily R Boniface ${ }^{1}$, MPH; Lisa Yin Han ${ }^{2,3}, \mathrm{PhD}$; Jonathan Albright ${ }^{4}, \mathrm{PhD}$; Nora Doty ${ }^{5}$, MD, MPH; Blair G Darney ${ }^{1,6,7}$, PhD, MPH

\footnotetext{
${ }^{1}$ Department of Obstetrics and Gynecology, Oregon Health and Science University, Portland, OR, United States

${ }^{2}$ Department of English, Arizona State University, Tempe, AZ, United States

${ }^{3}$ Department of Film and Media Studies, University of California-Santa Barbara, Santa Barbara, CA, United States

${ }^{4}$ Tow Center for Digital Journalism, Graduate School of Journalism, Columbia University, New York, NY, United States

5 Jersey Shore University Medical Center, Department of Obstetrics and Gynecology, Neptune, NJ, United States

${ }^{6}$ Center for Population Health Research, National Institute of Public Health, Cuernavaca, Mexico

${ }^{7}$ School of Public Health, Oregon Health and Science University-Portland State University, Portland, OR, United States
}

\section{Corresponding Author:}

Lisa Yin Han, PhD

Department of English

Arizona State University

Ross-Blakley Hall

1102 S McAllister Ave

Tempe, AZ, 85281

United States

Phone: 17202011533

Email: 1yhan@asu.edu

\section{Abstract}

Background: People use the internet as a primary source for learning about medical procedures and their associated safety profiles and risks. Although abortion is one of the most common procedures worldwide among women in their reproductive years, it is controversial and highly politicized. Substantial scientific evidence demonstrates that abortion is safe and does not increase a woman's future risk for depressive disorders or infertility. The extent to which information found on the internet reflects these medical facts in a trustworthy and unbiased manner is not known.

Objective: The purpose of this study was to collate and describe the trustworthiness and political slant or bias of web-based information about abortion safety and risks of depression and infertility following abortion.

Methods: We performed a cross-sectional study of internet websites using 3 search topics: (1) is abortion safe?, (2) does abortion cause depression?, and (3) does abortion cause infertility? We used the Google Adwords tool to identify the search terms most associated with those topics and Google's search engine to generate databases of websites related to each topic. We then classified and rated each website in terms of content slant (pro-choice, neutral, anti-choice), clarity of slant (obvious, in-between, or difficult/can't tell), trustworthiness (rating scale of 1-5, 5=most trustworthy), type (forum, feature, scholarly article, resource page, news article, blog, or video), and top-level domain (.com, .net, .org, .edu, .gov, or international domain). We compared website characteristics by search topic (safety, depression, or infertility) using bivariate tests. We summarized trustworthiness using the median and IQR, and we used box-and-whisker plots to visually compare trustworthiness by slant and domain type.

Results: Our search methods yielded a total of 111, 120, and 85 unique sites for safety, depression, and infertility, respectively. Of all the sites $(n=316), 57.3 \%(181 / 316)$ were neutral, $35.4 \%(112 / 316)$ were anti-choice, and 7.3\% (23/316) were pro-choice. The median trustworthiness score was 2.7 (IQR 1.7-3.7), which did not differ significantly across topics $(P=.409)$. Anti-choice sites were less trustworthy (median score 1.3, IQR 1.0-1.7) than neutral (median score 3.3, IQR 2.7-4.0) and pro-choice (median score 3.7, IQR 3.3-4.3) sites. Anti-choice sites were also more likely to have slant clarity that was "difficult to tell" (41/112, $36.6 \%)$ compared with neutral $(25 / 181,13.8 \%)$ or pro-choice $(4 / 23,17.4 \% ; P<.001)$ sites. A negative search term used for the topic of safety (eg, "risks") produced sites with lower trustworthiness scores than search terms with the word "safety" (median score 1.7 versus 3.7 , respectively; $P<.001)$. 
Conclusions: People seeking information about the safety and potential risks of abortion are likely to encounter a substantial amount of untrustworthy and slanted/biased abortion information. Anti-choice sites are prevalent, often difficult to identify as anti-choice, and less trustworthy than neutral or pro-choice sites. Web searches may lead the public to believe abortion is riskier than it is.

(J Med Internet Res 2020;22(10):e20619) doi: $\underline{10.2196 / 20619}$

\section{KEYWORDS}

internet; abortion; media; websites; infodemiology; infodemic; quality of health information; bias in patient education

\section{Introduction}

The internet is the first source the public turns to for medical information [1-3]. At least $70 \%$ of adults who use the internet use it for health information research, with $43 \%$ of them seeking information about specific treatments or procedures [4]. Although the internet is a vast repository of searchable information, there is often incorrect, deliberately misleading, conflicting, and/or hard to understand information [5]. Furthermore, public perception and knowledge is shaped by personalized internet experience, which is delimited by technology company algorithms [6-8]. Abortion is one of the most common medical procedures in the world. According to recent estimates, over 800,000 women in the United States choose an abortion each year [9]; even more consider abortion but do not obtain one [10]. Surgical procedures for abortion are referred to as aspiration, dilation, and curettage (D\&C), or dilation and evacuation (D\&E) if done later in pregnancy. For abortions in the first trimester of pregnancy (up to 10 weeks), medications are used [11]. The best scientific evidence clearly demonstrates that induced abortion is safe [12,13] and that abortion does not increase a woman's future risk for disorders such as depression, anxiety, or suicidality [14], or secondary infertility $[15,16]$. Only low-quality and/or discredited studies suggest otherwise [17,18]. The risks of abortion do increase with the gestational age of the pregnancy, but abortion at any gestational age is safer than childbirth [12].

Despite these facts, many antiabortion arguments rest on misinformation regarding the safety and health consequences of abortion [19]. Crisis pregnancy centers (CPCs) - organizations that try to intercept women who are considering an abortion —often describe abortion as dangerous or deadly in order to dissuade women from choosing to obtain an abortion [20]. In addition, false or misleading information on the internet about abortion continues to exert an influence on public debates and policy [21]. Previous studies have examined web-based abortion information, focusing on the quality of information available for self-referral (on CPC websites, specifically) and about D\&E procedures [20,22,23]. These studies found frequent inaccuracies and a lack of comprehensive information about abortion on the internet. However, the studies were limited by small data samples [23,24] or narrow inquiries on specific websites [10]. It remains unclear exactly what a search about abortion safety or potential subsequent risks would yield in terms of websites, as well as the trustworthiness and accuracy of information contained on them. The purpose of this study was to collate and describe the web-based ecosystem about abortion in terms of the trustworthiness and bias about abortion safety and risks. We focused on websites that provided information related to three questions: (1) is abortion safe?, (2) does abortion cause depression?, and (3) does abortion cause infertility? We chose safety, infertility, and depression for our case studies because the existing medical evidence is very clear; the mainstream scientific consensus is that abortion is safe and does not cause subsequent infertility or depression [25]. However, these questions continue to be disputed in public discourse and provide an opportunity to evaluate the quality of website information.

\section{Methods}

This cross-sectional study had two phases: first, we created a database of websites from searches about abortion and safety, depression, and infertility; second, we used the ecosystem database that we created to classify websites in terms of content trustworthiness, political slant on abortion, type of site, and top-level domain.

\section{Website Database}

We utilized several steps to create our website database in order to minimize bias and most broadly capture what the general public would encounter while searching on the web (Figure 1). First, we used Google's Adwords tool, a free Google advertising tool that allows advertisers to associate their ads with search terms based on the popularity of the term. For a given topic, the keyword tool identifies the most commonly used search terms with a topic based on historical search data [26]. We selected 5 search terms for each of our 3 keyword combinations (abortion safety, abortion depression, and abortion infertility) based on their frequency as identified by Google Adwords and relevance (Figure 2). Next, we conducted Google searches using these phrases on August 31, 2018, and compiled website results for each of our search terms. In order to remove search term personalization, each search was performed using a cookie-cleared Google Chrome (version 10.8) browser in incognito mode combined with a free virtual private network called Windscribe (version 1.82) in order to reduce locational bias as well as anonymize our internet protocol addresses. For each search phrase, we extracted the top 25 page-ranked results, noting multiple occurrences. Each link was then imported into a spreadsheet using MozBar (Moz Inc), a Chrome extension that also produced titles, brief excerpts, and a search position number for each link based on its proximity to the top of the Google page. We produced a database for each of our topics (safety, depression, infertility) based on this search methodology. 
Figure 1. Workflow of website selection for the analysis.

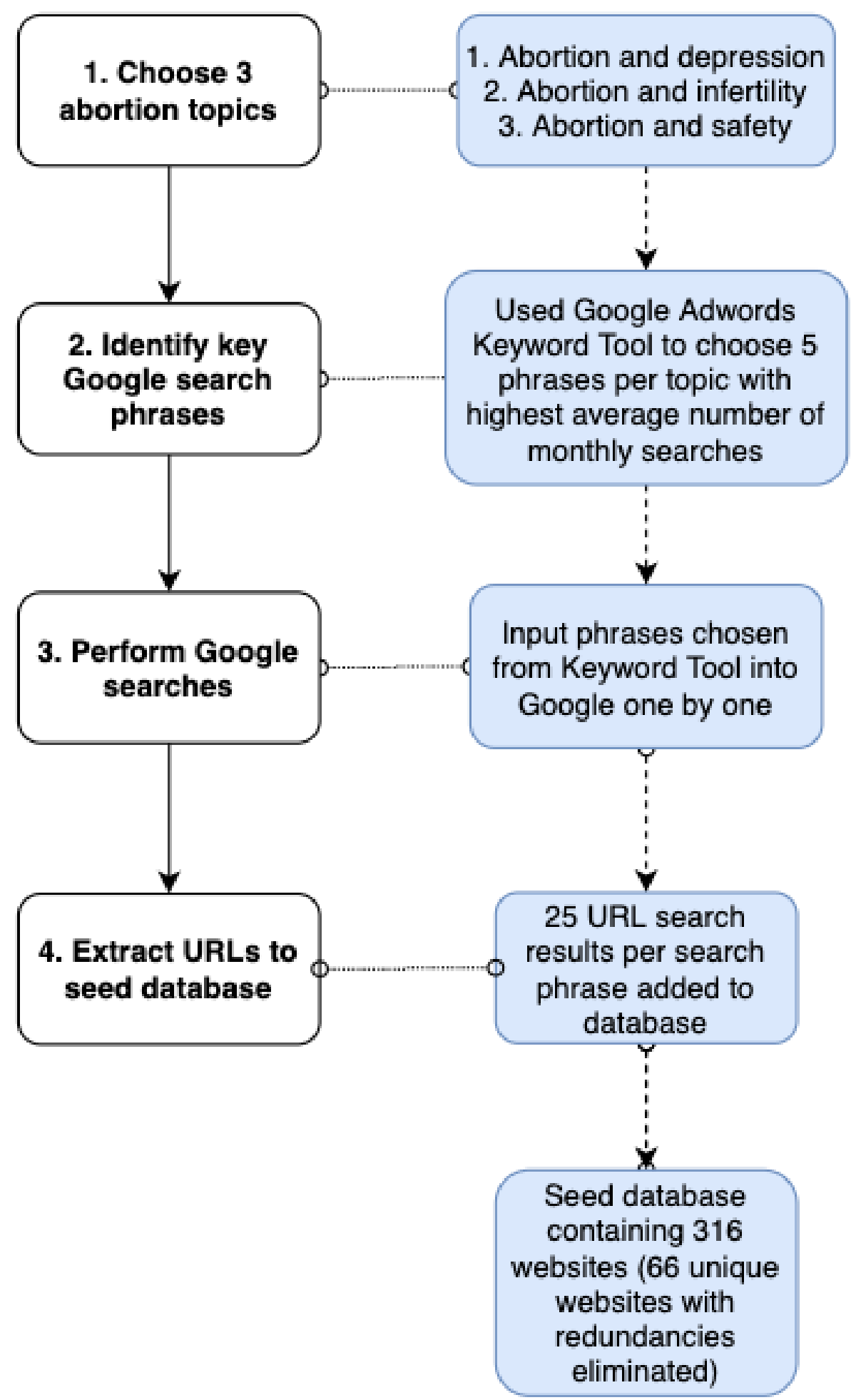


Figure 2. Circular dendrogram of unique websites found in the analysis. The center depicts the 3 keywords used to identify the most commonly searched terms for those topics, the middle ring includes the search phrases that were used for the Google search, and the outer ring depicts the URL search results for each search phrase.

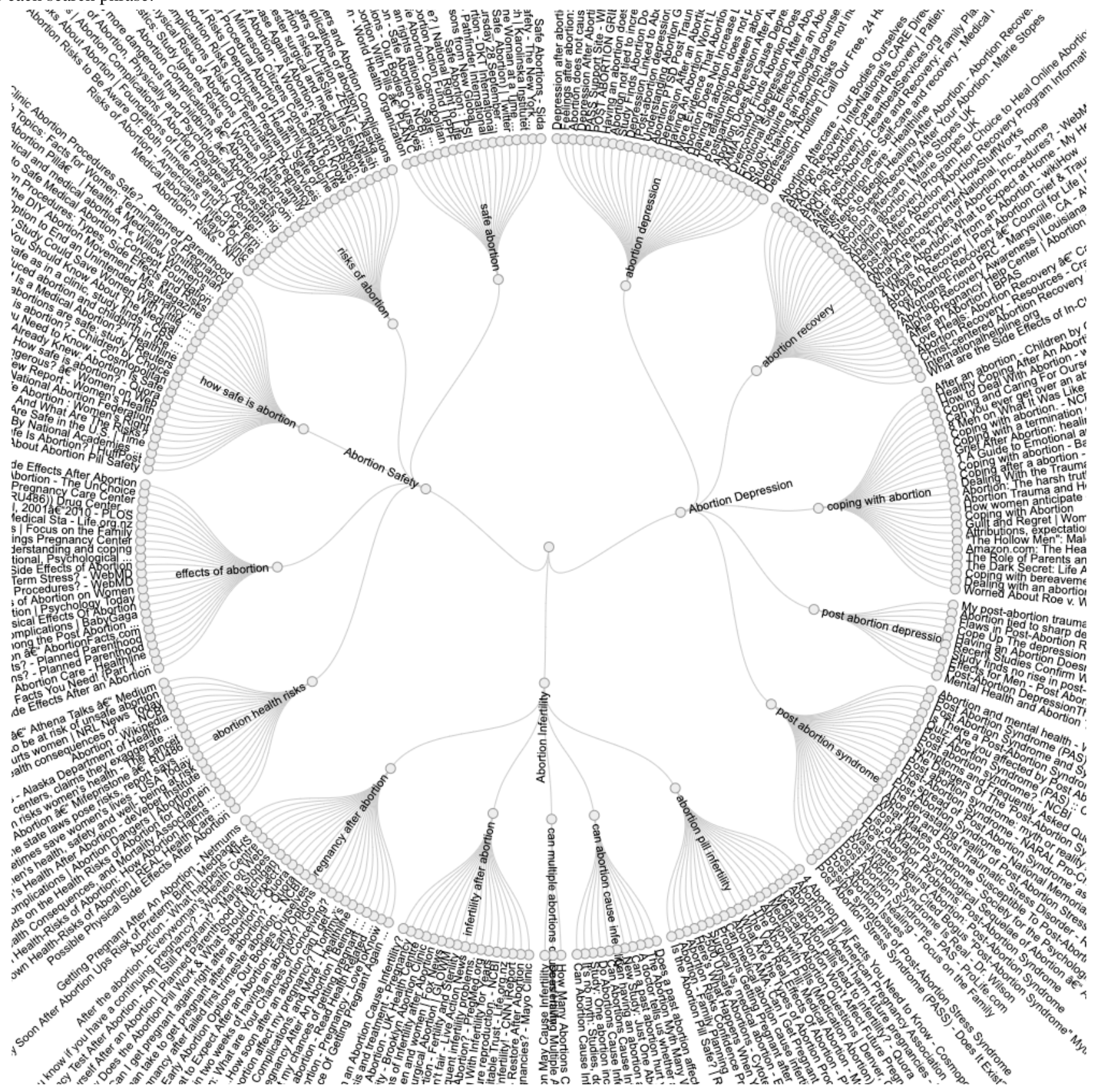

\section{Website Categorization}

We next classified and rated each website in the database. We rated websites on 5 metrics: (1) slant, (2) slant clarity, (3) trustworthiness, (4) type, and (5) domain. For slant, a website was determined to have a pro-choice or anti-choice bias if either (a) information was given in a biased or dramatic fashion (eg, an anti-choice site describing the procedure as "tearing the baby from the womb"), or (b) the website displayed an opinion regarding the provision of abortion and its legality (eg, a pro-choice site stating that abortion should be free and legal for all women); otherwise, the website was considered neutral. We assigned a slant clarity rating based on how easy it was to discern the website's slant (obvious, in-between, or difficult/can't tell). We scored trustworthiness on a rating scale from 1 to 5 , with 5 being most trustworthy based on factors including the content and the source of the content (eg, creators, references, or affiliation with health care organizations or health care professionals) [27-29]. These factors were informed by existing systematic criteria developed by prior studies of media credibility and disinformation [30]. The domain was the generic top-level domain of the site (.com/.net, .edu, .gov, .org, or a domain that identified the website as international, such as .uk or .nz). Finally, investigators loosely categorized websites based on 7 descriptive "types," including forum, feature, scholarly article, resource page, news article, blog, and video. Two investigators independently coded all of the websites. In the event of disagreement, a third researcher arbitrated the categorization. In the case of trustworthiness, the scores from investigators were averaged. All three researchers have published abortion-related research previously. 


\section{Data Analysis}

First, we created a visualization of the websites and their parent search terms and topics using RAWGraphs. Next, we compared website characteristics overall and by search topic (safety, depression, or infertility) using Pearson chi-square test or Fisher exact test for all categorical classifications to compare characteristics across topics. We summarized trustworthiness, measured on a 5-point scale, using the median and IQR. For each search topic, we also assessed the distribution of websites based on the content's slant for the 5 query terms, and then compared the trustworthiness of query term results using Kruskal-Wallis and Wilcoxon rank sum tests. We used box-and-whisker plots to visually compare trustworthiness by slant and by domain type. Finally, we tabulated websites according to their slant and slant clarity, comparing distributions using Fisher exact test, and then used a bar graph to examine website counts graphically. The study was reviewed and approved by the Oregon Health and Science University's institutional review board and was deemed not human subjects research.

\section{Results}

After removing duplicates, our search methods yielded a total of 111, 120, and 85 unique sites for safety, depression, and infertility, respectively. Figure 2 provides a visualization of these websites and their parent search terms and topic (see Multimedia Appendix 1 for full list of sites with URLs). While the majority of sites had a neutral slant (181/316, 57.3\%) overall, the slant distribution differed by topic, with a higher proportion of sites about safety and depression having an anti-choice slant (Table 1). Approximately $40 \%$ of sites about safety and depression had an anti-choice slant (safety: 44/111, 39.6\%; depression: 51/120, 42.5\%), compared with $15.3 \%$ (17/111) and $3.3 \%(4 / 120)$ of the safety and depression sites, respectively, being categorized as having a pro-choice slant. Infertility had the highest proportion of neutral sites $(66 / 85,77.7 \%)$. In terms of website type, we categorized the majority of websites as resource pages $(158 / 316,50.8 \%)$. Commercial (.com/.net) $(154 / 316,48.7 \%)$ and organization (.org) $(101 / 316,32.0 \%)$ sites accounted for the majority of domain types. While we did not specifically perform an analysis of slant by web address (URL), we noticed that many of the anti-choice sites came from generic-appearing addresses (eg, americanpregnancy.org, adviceandaid.com). One state health department site (Alaska) was rated by our researchers as being anti-choice.

We found that the median score for trustworthiness of the websites was 2.7 (IQR 1.7-3.7), which did not differ significantly across topics (safety: median score 3.0, IQR 1.7-3.7; depression: median score 2.3, IQR 1.7-3.7; infertility: median score 2.7 , IQR 1.7-3.7; $P=.409$ ). Agreement in trustworthiness scores among our coders was $71.8 \%, 70.0 \%$, and $80.9 \%$ for safety, depression, and infertility, respectively. Of the 316 sites in our sample, only $59(18.7 \%)$ sites received median trustworthiness scores of 4 or more (data not shown). The trustworthiness rating of sites was different by slant and by domain type (Figure 3). Overall, anti-choice sites had lower trustworthiness scores (median score 1.3, IQR 1.0-1.7) compared with neutral (median score 3.3, IQR 2.7-4.0) and pro-choice (median score 3.7, IQR 3.3-4.3) sites. Sites that came from educational institutions (.edu) were consistently given higher trustworthiness scores (median score 4.3, IQR 3.7-4.3), while other domains received overall lower and more widely distributed trustworthiness scores, with commercial sites (.com/.net) considered to be the least trustworthy (median score 2.3, IQR 1.3-3.3). 
Table 1. Website characteristics by search topic $(n=316)$.

\begin{tabular}{|c|c|c|c|c|c|}
\hline Characteristic & Overall & Safety $(n=111)^{a}$ & Depression $(n=120)$ & Infertility $(n=85)$ & $P$ value \\
\hline Slant, n (\%) & & & & & $<.001$ \\
\hline Pro-choice & $23(7.3)$ & $17(15.3)$ & $4(3.3)$ & $2(2.4)$ & \\
\hline Neutral & $181(57.3)$ & $50(45.1)$ & $65(54.2)$ & $66(77.7)$ & \\
\hline Anti-choice & $112(35.4)$ & $44(39.6)$ & $51(42.5)$ & $17(20.0)$ & \\
\hline Slant clarity, n (\%) & & & & & .002 \\
\hline Obvious & $121(38.3)$ & $41(36.9)$ & $49(40.8)$ & $31(36.5)$ & \\
\hline In-between & $125(39.6)$ & $49(44.1)$ & $33(27.5)$ & $43(50.6)$ & \\
\hline Difficult/can't tell & $70(22.1)$ & $21(18.9)$ & $38(31.7)$ & $11(12.9)$ & \\
\hline Domain, n (\%) & & & & & .002 \\
\hline Commercial (.com/.net) & $154(48.7)$ & $45(40.5)$ & $60(50.0)$ & $49(57.7)$ & \\
\hline International & $42(13.3)$ & $8(7.2)$ & $17(14.2)$ & $17(20.0)$ & \\
\hline Education (.edu) & $5(1.6)$ & $2(1.8)$ & $1(0.8)$ & $2(2.4)$ & \\
\hline Government (.gov) & $14(4.4)$ & $8(7.2)$ & $4(3.3)$ & $2(2.4)$ & \\
\hline Organization (.org) & $101(32.0)$ & $48(43.2)$ & $38(31.7)$ & 15 (17.7) & \\
\hline Page type, n (\%) & & & & & .007 \\
\hline News article & $30(9.7)$ & $12(11.3)$ & $13(10.8)$ & $5(5.9)$ & \\
\hline Forum & $17(5.5)$ & $2(1.9)$ & $2(1.7)$ & $13(15.3)$ & \\
\hline $\mathrm{B} \log$ & $16(5.1)$ & $5(4.7)$ & $8(6.7)$ & $3(3.5)$ & \\
\hline Feature & $63(20.3)$ & $21(19.8)$ & $20(16.7)$ & $22(25.9)$ & \\
\hline Scholarly article & $25(8.0)$ & $9(8.5)$ & $11(9.2)$ & $5(5.9)$ & \\
\hline Resource page & $158(50.8)$ & $57(53.8)$ & $64(53.3)$ & $37(43.5)$ & \\
\hline Video & $2(0.6)$ & $0(0)$ & $2(1.7)$ & $0(0)$ & \\
\hline Trustworthiness, median (IQR) & $2.7(1.7-3.7)$ & $3.0(1.7-3.7)$ & $2.3(1.7-3.7)$ & $2.7(1.7-3.7)$ & .409 \\
\hline
\end{tabular}

${ }^{\mathrm{a}}$ Five websites in the safety category were missing data about page type. 
Figure 3. Box-and-whisker plots comparing trustworthiness of online abortion resources by slant and domain type (n=316). Trustworthiness was scored on a scale of 1 (least trustworthy) to 5 (most trustworthy). The central line in each box marks the median trustworthiness score; upper and lower box edges mark the 75th and 25th percentile, respectively; whiskers indicate $150 \%$ of the interquartile range and outliers are shown as individual points. Int'l: international domain (eg, .uk, .nz, .id).

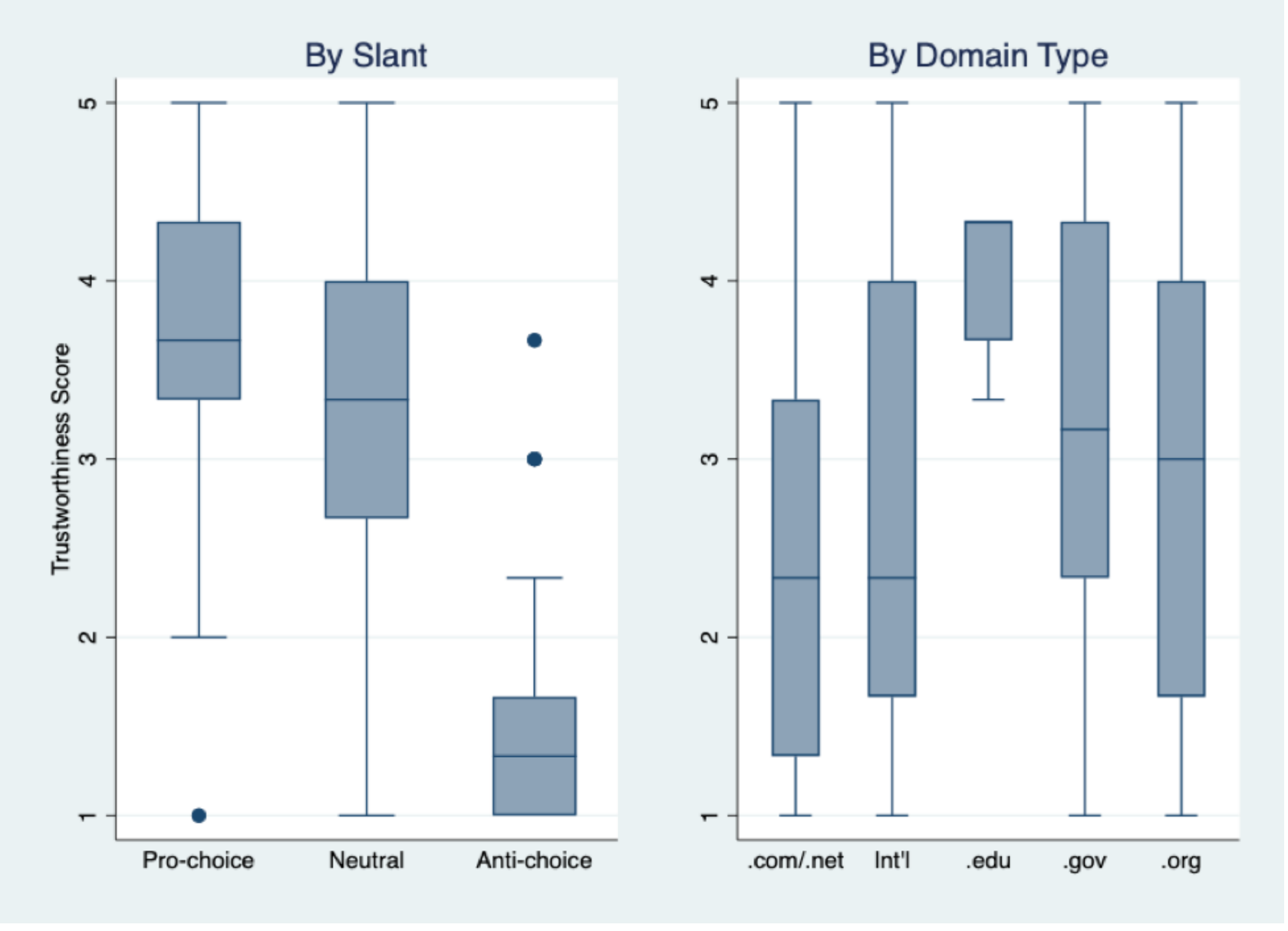

We also examined our results using specific search query terms and noted that for searches on safety and infertility, trustworthiness scores were significantly different across query search terms (Table 2). For searches focused on abortion safety, including the word "safe" resulted in sites with significantly higher trustworthiness scores (median score 3.7, IQR 3.3-4.3) compared with searches that included the more negative word "risks" (median 1.7, IQR 1.0-3.3; Wilcoxon rank sum $P<.001$ ). Anti-choice sites appeared more frequently with negative search terms, such as "risks of abortion" (17/23, 73.9\%), compared with when the word "safe" was included in the search term, such as, "How safe is abortion?" (1/27, 3.7\%) (Table 2).

Finally, we found that slant clarity, or how difficult it was to discern the anti-choice, neutral, or pro-choice slant of a website, varied significantly both by topic and by slant. In regard to the topic, there were many more depression websites with a "difficult/can't tell" slant compared with sites about safety and infertility $(31.7 \%$ versus $18.9 \%$ and $12.9 \%$, respectively; $P=.002)$. However, all 3 topic categories contained clarity ratings of "obvious" for fewer than one-half of the sites (Table 1). In terms of slant, anti-choice sites were more likely to have slant clarity that was "difficult/can't tell" $(41 / 112,36.6 \%)$ compared with neutral $(25 / 181,13.8 \%)$ or pro-choice $(4 / 23,17.4 \%)$ sites $(P<.001)$ (Figure 4). 
Table 2. Search query terms used and associated trustworthiness and website slant for each search topic.

\begin{tabular}{|c|c|c|c|c|c|c|}
\hline Topic and search query terms & Total, n (\%) & $\begin{array}{l}\text { Pro-choice, } \\
\mathrm{n}(\%)\end{array}$ & Neutral, n (\%) & $\begin{array}{l}\text { Anti-choice, } \mathrm{n} \\
(\%)\end{array}$ & $\begin{array}{l}\text { Trustworthiness, median } \\
\text { (IQR) }\end{array}$ & $P$ value \\
\hline Safety $(n=111)$ & & & & & & $<.001$ \\
\hline Abortion health risks & $19(17.1)$ & $1(5.3)$ & $7(36.8)$ & $11(57.9)$ & $2.3(1.7-3.3)$ & \\
\hline Effects of abortion & $24(21.6)$ & $0(0)$ & $10(41.7)$ & $14(58.3)$ & $1.7(1.0-3.0)$ & \\
\hline How safe is abortion? & $27(24.4)$ & $5(18.5)$ & $21(77.8)$ & $1(3.7)$ & $3.7(3.0-4.3)$ & \\
\hline Risks of abortion & $23(20.7)$ & $0(0)$ & $6(26.1)$ & $17(73.9)$ & $1.3(1.0-2.3)$ & \\
\hline Safe abortion & $18(16.2)$ & $11(61.1)$ & $6(33.3)$ & $1(5.6)$ & $3.7(3.7-4.3)$ & \\
\hline Depression $(n=120)$ & & & & & & .143 \\
\hline Abortion depression & $28(23.3)$ & $0(0)$ & $17(60.7)$ & $11(39.3)$ & $3.2(1.7-3.7)$ & \\
\hline Abortion recovery & $29(24.2)$ & $0(0)$ & $14(48.3)$ & $15(51.7)$ & $2.3(1.7-3.7)$ & \\
\hline Coping with abortion & $26(21.7)$ & $0(0)$ & $21(80.8)$ & $5(19.2)$ & $3.2(1.7-3.7)$ & \\
\hline Post-abortion depression & $10(8.3)$ & $0(0)$ & $6(60.0)$ & $4(40.0)$ & $2.2(1.3-3.3)$ & \\
\hline Post-abortion syndrome & $27(22.5)$ & $4(14.8)$ & $7(25.9)$ & $16(59.3)$ & $1.7(1.3-3.0)$ & \\
\hline Infertility $(n=85)$ & & & & & & .005 \\
\hline Abortion pill infertility & $19(22.4)$ & $1(5.3)$ & $15(78.9)$ & $3(15.8)$ & $3.7(2.0-4.3)$ & \\
\hline Can abortion cause infertility? & $11(12.9)$ & $0(0)$ & $8(72.7)$ & $3(27.3)$ & $2.0(1.7-3.3)$ & \\
\hline $\begin{array}{l}\text { Can multiple abortions cause infer- } \\
\text { tility? }\end{array}$ & $15(17.6)$ & $0(0)$ & $11(73.3)$ & $4(26.7)$ & $1.7(1.0-2.7)$ & \\
\hline Infertility after abortion & $17(20.0)$ & $1(5.9)$ & $10(58.8)$ & $6(35.3)$ & $2.3(1.0-3.3)$ & \\
\hline Pregnancy after abortion & $23(27.1)$ & $0(0)$ & $22(95.7)$ & $1(4.3)$ & $3.0(2.3-3.7)$ & \\
\hline
\end{tabular}

Figure 4. Counts of online abortion resources by slant and slant clarity $(\mathrm{n}=316)$.

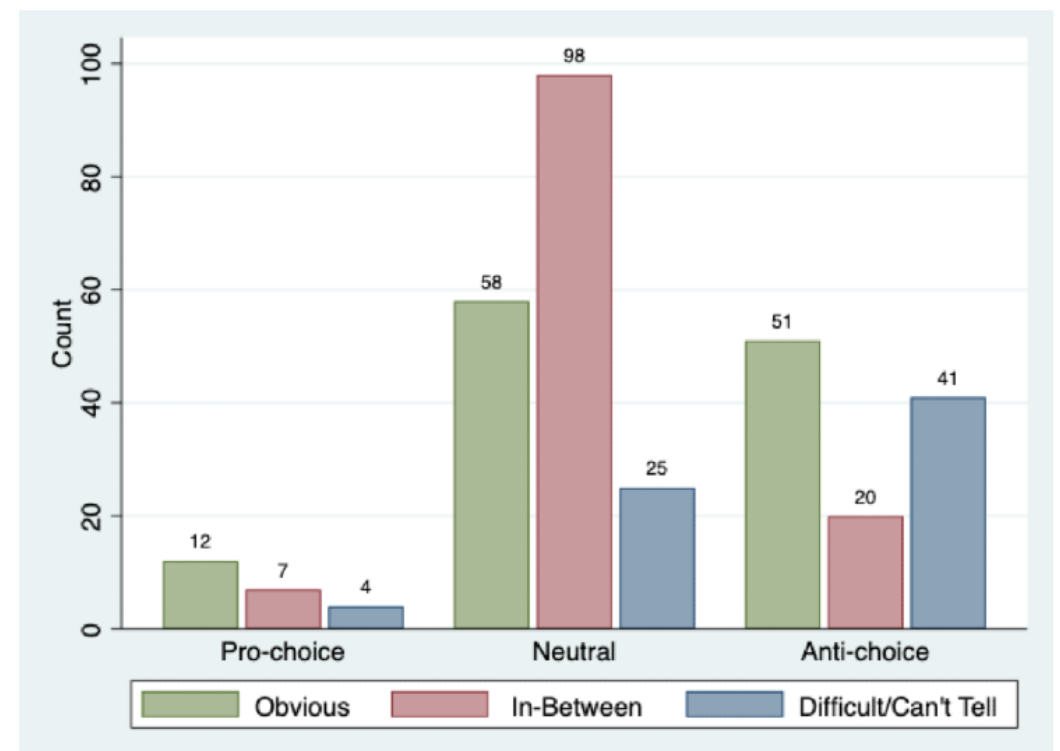

\section{Discussion}

\section{Principal Findings}

Our study of websites that provide information about safety of abortion or subsequent risks of depression or infertility found that overall, $35.4 \%(112 / 316)$ of sites had an anti-choice slant. Anti-choice sites were less trustworthy, and the clarity of their stance was also more difficult to determine. Our data also show that people seeking information about the safety and potential risks of abortion are likely to find substantial amounts of untrustworthy abortion information; the overall median trustworthiness score of these sites was 2.7 (on a scale of 1-5), with a wide range (IQR 1.7-3.7).

Our results are consistent with other examples of intentionally disseminated abortion disinformation. CPCs have an antiabortion agenda but use neutral language and advertising to appear as if they are a normal medical clinic [20]. In our study, almost two-thirds $(71 / 112,63.4 \%)$ of anti-choice sites were categorized 
as resource pages and many derived from web addresses that appeared generic and neutral. Moreover, one state health department site rated as anti-choice, which demonstrates that even official governmental sites can be biased sources of information. These findings suggest that anti-choice sites may be trying to obscure their biases or appear as neutral information brokers. Based on the high number of "difficult to tell" sites in our data sets, we need more research to understand the characteristics of anti-choice sites that create this effect.

We know that in the case of abortion, false or misleading information continues to play a role in public debates and government legislation. For example, Targeted Regulation of Abortion Providers (TRAP) laws, or costly and burdensome regulations aiming to restrict access to abortions by dictating how, by whom, and when abortions can be provided, are often based on false health claims but framed as protecting patient safety [31]. The internet is one of the most important propagators of false information. Previous research has shown that media is more influential among young people (aged 13 to 29 years) than friends, family, and health care providers when it comes to learning about abortion [32]. However, there is also evidence that exposing the public to more evidence-based information on abortion can change opinions about the provision and regulation of abortion services [33]. Thus, efforts to address the spread of false information and strengthen the presence of evidence-based information on abortion can have real impact. Our results can help inform clinicians and others who work in the abortion field about likely information gaps [34]. Moreover, health organizations that seek to disseminate evidence-based information may want to conduct regular search audits such as this in order to optimize their search positions to reach a broader audience.

\section{Limitations}

Our study results should be interpreted with the following limitations in mind. We used expert ratings to gain insight into the abortion online media ecosystem. All of our experts are engaged in abortion-related research and two-thirds of our experts are abortion providers. We recognize that non-experts may have rated and classified these same websites differently. However, our expert ratings provide a benchmark for future work that explores how non-experts perceive the information contained in these websites. We also acknowledge that trustworthiness scores could be confounded with slant and that sites with obvious anti-choice slants may have been rated with lower trustworthiness scores based on the impression of bias. However, it is difficult to blind these components from each other and we wanted to provide some kind of measure of quality for the information we encountered. We recognize that our study provides only a cross-sectional snapshot of the internet. While specific site rankings may be driven by news cycles, we believe the overall picture is unlikely to change [35]. We also acknowledge that while we took measures to anonymize the search results, individuals will receive different results based on their previous search history, and the majority will not scroll past the first page. However, our database sizes captured approximately the first 8 to 12 pages of search results for a given topic. Finally, while our focus was on websites, websites alone do not fully address the digital means through which abortion information is shared. In particular, social networking platforms are critical sources [36]. The strengths of our study include the use of a systematic and rigorous approach to create our website database, incorporation of multiple topic areas, and focus on content trustworthiness and bias.

Our results provide insight into the online abortion ecosystem. We find that anti-choice sites are prevalent, often hard to identify as anti-choice (difficult slant clarity), and less trustworthy than neutral and pro-choice sites. Additionally, the search terms a user chooses may play a substantial role in the quality and bias of websites they see. Our results help us understand how the internet may impact public perceptions and knowledge about the safety of abortion and potential risks of depression and infertility. Our findings suggest that web searches may lead people to perceive abortion procedures as more dangerous and riskier than they actually are.

\section{Acknowledgments}

This study was funded by The Society for Family Planning.

\section{Conflicts of Interest}

None declared.

\section{Multimedia Appendix 1}

Full list of websites and site ratings.

[XLSX File (Microsoft Excel File), 87 KB-Multimedia Appendix 1]

\section{References}

1. Rupert DJ, Gard Read J, Amoozegar JB, Moultrie RR, Taylor OM, O'Donoghue AC, et al. Peer-Generated Health Information: The Role of Online Communities in Patient and Caregiver Health Decisions. J Health Commun 2016 Nov;21(11):1187-1197 [FREE Full text] [doi: 10.1080/10810730.2016.1237592] [Medline: 27805496]

2. Ziebland S, Powell J, Briggs P, Jenkinson C, Wyke S, Sillence E, et al. Examining the role of patients' experiences as a resource for choice and decision-making in health care: a creative, interdisciplinary mixed-method study in digital health. Programme Grants Appl Res 2016 Nov;4(17):1-214. [doi: 10.3310/pgfar04170] 
3. McMullan M. Patients using the Internet to obtain health information: how this affects the patient-health professional relationship. Patient Educ Couns 2006 Oct;63(1-2):24-28. [doi: 10.1016/j.pec.2005.10.006] [Medline: 16406474]

4. Fox S, Duggan M. Health Online 2013 Internet. Pew Res Cent Internet Sci Tech. Washington, D.C; 2013 Jan 15. URL: http://www.pewinternet.org/2013/01/15/health-online-2013/ [accessed 2020-04-21]

5. Benigeri M. Shortcomings of health information on the Internet. Health Promotion International 2003 Dec 01;18(4):381-386. [doi: 10.1093/heapro/dag409]

6. Bessi A, Ferrara E. Social bots distort the 2016 U.S. Presidential election online discussion. First Monday 2016 Nov 03:NA-NA [FREE Full text] [doi: 10.5210/fm.v21i11.7090]

7. Gottfried J, Shearer E. News Use Across Social Media Platforms 2016 Internet. Pew Res Cent Journal Proj. 2016 May 26. URL: http://www.journalism.org/2016/05/26/news-use-across-social-media-platforms-2016/ [accessed 2020-04-21]

8. Christen CT, Huberty KE. Media Reach, Media Influence? The Effects of Local, National, and Internet News on Public Opinion Inferences. 2016 Jun 25;84(2):315-334. [doi: 10.1177/107769900708400208]

9. Jones RK, Witwer E, Jerman J. Abortion Incidence and Service Availability in the United States, 2017. Guttmacher Institute. New York: Guttmacher Institute; 2019 Sep. URL: https://www.guttmacher.org/report/ abortion-incidence-service-availability-us-2017 [accessed 2020-04-21]

10. Roberts SCM, Johns NE, Williams V, Wingo E, Upadhyay UD. Estimating the proportion of Medicaid-eligible pregnant women in Louisiana who do not get abortions when Medicaid does not cover abortion. BMC Women's Health 2019 Jun 19;19(1):78. [doi: 10.1186/s12905-019-0775-5]

11. Committee on Health Care for Underserved Women. ACOG Committee Opinion No. 613: Increasing access to abortion. Obstet Gynecol 2014 Nov;124(5):1060-1065. [doi: 10.1097/01.AOG.0000456326.88857.31] [Medline: 25437742]

12. Raymond EG, Grimes DA. The Comparative Safety of Legal Induced Abortion and Childbirth in the United States. 2012;119(2, Part 1):215-219. [doi: 10.1097/aog.0b013e31823fe923]

13. Jatlaoui TC, Ewing A, Mandel MG, Simmons KB, Suchdev DB, Jamieson DJ, et al. Abortion Surveillance — United States, 2013. MMWR Surveill. Summ 2016 Nov 25;65(12):1-44. [doi: 10.15585/mmwr.ss6512a1]

14. Steinberg JR, McCulloch CE, Adler NE. Abortion and mental health: findings from The National Comorbidity Survey-Replication. Obstet Gynecol 2014 Feb;123(2 Pt 1):263-270 [FREE Full text] [doi: 10.1097/AOG.0000000000000092] [Medline: 24402590]

15. Frank P, McNamee R, Hannaford PC, Kay CR, Hirsch S. The effect of induced abortion on subsequent fertility. Br J Obstet Gynaecol 1993 Jun;100(6):575-580. [doi: 10.1111/j.1471-0528.1993.tb15313.x] [Medline: $\underline{8334095]}$

16. Lurie S, Levy R, Katz Z, Appelman Z, Insler V. The influence of midtrimester termination of pregnancy on subsequent fertility: four to five years follow-up. Contraception 1994 Sep;50(3):239-241. [doi: 10.1016/0010-7824(94)90069-8]

17. Coleman PK. Abortion and mental health: quantitative synthesis and analysis of research published 1995-2009. Br J Psychiatry 2011 Sep;199(3):180-186. [doi: 10.1192/bjp.bp.110.077230] [Medline: 21881096]

18. Koch E, Chireau M, Pliego F, Stanford J, Haddad S, Calhoun B, et al. Abortion legislation, maternal healthcare, fertility, female literacy, sanitation, violence against women and maternal deaths: a natural experiment in 32 Mexican states. BMJ Open 2015 Feb 23;5(2):e006013-e006013. [doi: 10.1136/bmjopen-2014-006013]

19. AbortionFacts.com. URL: http://www.abortionfacts.com/ [accessed 2018-01-05]

20. Bryant AG, Narasimhan S, Bryant-Comstock K, Levi EE. Crisis pregnancy center websites: Information, misinformation and disinformation. Contraception 2014 Dec;90(6):601-605. [doi: 10.1016/j.contraception.2014.07.003]

21. Conti JA, Cahill E. Abortion in the media. Curr Opin Obstet Gynecol 2017 Dec;29(6):427-430. [doi: 10.1097/GCO.0000000000000412] [Medline: 28915157]

22. Dodge LE, Phillips SJ, Neo DT, Nippita S, Paul ME, Hacker MR. Quality of Information Available Online for Abortion Self-Referral. 2018;132(6):1443-1452. [doi: 10.1097/aog.0000000000002950]

23. Carlsson T, Axelsson O. Patient Information Websites About Medically Induced Second-Trimester Abortions: A Descriptive Study of Quality, Suitability, and Issues. J Med Internet Res 2017 Jan 10;19(1):e8. [doi: 10.2196/jmir.6380]

24. Han L, Rodriguez M, Han L. Tweeting PP: an analysis of the 2015-2016 Planned Parenthood controversy on Twitter. Contraception 2016 Oct;94(4):399. [doi: 10.1016/j.contraception.2016.07.064]

25. National Academies of Sciences, Engineering, and Medicine, Health and Medicine Division, Board on Health Care Services, Board on Population Health and Public Health Practice, Committee on Reproductive Health Services: Assessing the Safety and Quality of Abortion Care in the U.S.. The Safety and Quality of Abortion Care in the United States. Washington, DC: National Academies Press; Mar 16, 2018:1-187.

26. Use Keyword Planner. Google Ads Help. URL: https://support.google.com/google-ads/answer/7337243?hl=en [accessed 2019-04-09]

27. Ahmad R, Komlodi A, Wang J, Hercegfi K. The impact of user experience levels on web credibility judgments. Proc. Am. Soc. Info. Sci. Tech 2011 Feb 03;47(1):1-4. [doi: 10.1002/meet.14504701180]

28. Song H, Omori K, Kim J, Tenzek KE, Morey HJ, Lin W, et al. Trusting Social Media as a Source of Health Information: Online Surveys Comparing the United States, Korea, and Hong Kong. J Med Internet Res 2016 Mar 14;18(3):e25 [FREE Full text] [doi: 10.2196/jmir.4193] [Medline: 26976273] 
29. Pereira JL, Koski S, Hanson J, Bruera ED, Mackey JR. Internet Usage Among Women with Breast Cancer: An Exploratory Study. Clinical Breast Cancer 2000 Jul;1(2):148-153. [doi: 10.3816/cbc.2000.n.013]

30. Zimdars M. False, Misleading, Clickbait-y, and/or Satirical "News" Sources. Google document. 2016 Nov 17. URL: https:/ /docs.google.com/document/d/10eA5-mCZLSS4MQY5QGb5ewC3VAL6pLkT53V_81ZyitM/preview [accessed 2020-04-21]

31. Targeted Regulation of Abortion Providers. Guttmacher Institute. Washington, D.C: Guttmacher Institute; 2020 Oct 01. URL: https://www.guttmacher.org/state-policy/explore/targeted-regulation-abortion-providers [accessed 2020-10-01]

32. Altshuler AL, Gerns Storey HL, Prager SW. Exploring abortion attitudes of US adolescents and young adults using social media. Contraception 2015 Mar;91(3):226-233. [doi: 10.1016/j.contraception.2014.11.009] [Medline: 25537853]

33. White K, Grossman D, Stevenson AJ, Hopkins K, Potter JE. Does information about abortion safety affect Texas voters' opinions about restrictive laws? A randomized study. Contraception 2017 Dec;96(6):381-387. [doi: 10.1016/j.contraception.2017.08.007]

34. Tan SS, Goonawardene N. Internet Health Information Seeking and the Patient-Physician Relationship: A Systematic Review. J Med Internet Res 2017 Jan 19;19(1):e9 [FREE Full text] [doi: 10.2196/jmir.5729] [Medline: 28104579]

35. Vaughan L. New measurements for search engine evaluation proposed and tested. 2004 Jul;40(4):677-691. [doi: 10.1016/s0306-4573(03)00043-8]

36. Majchrzak A, Faraj S, Kane GC, Azad B. The Contradictory Influence of Social Media Affordances on Online Communal Knowledge Sharing. J Comput-Mediat Comm 2013 Oct 18;19(1):38-55. [doi: 10.1111/jcc4.12030]
Abbreviations
CPCs: crisis pregnancy centers
D\&C: aspiration, dilation, and curettage
D\&E: dilation and evacuation
TRAP: Targeted Regulation of Abortion Providers

Edited by G Eysenbach; submitted 24.05.20; peer-reviewed by $Q$ Wu, M Jordan-Marsh; comments to author 11.08.20; revised version
received 28.08.20; accepted 22.09.20; published 26.10.20
Please cite as:
Han L, Boniface ER, Han LY, Albright J, Doty N, Darney BG
The Abortion Web Ecosystem: Cross-Sectional Analysis of Trustworthiness and Bias
J Med Internet Res 2020;22(10):e20619
URL: $\underline{\text { http://www.jmir.org/2020/10/e20619/ }}$
doi: $\underline{10.2196 / 20619}$
PMID: $\underline{3104002}$

CLeo Han, Emily R Boniface, Lisa Yin Han, Jonathan Albright, Nora Doty, Blair G Darney. Originally published in the Journal of Medical Internet Research (http://www.jmir.org), 26.10.2020. This is an open-access article distributed under the terms of the Creative Commons Attribution License (https://creativecommons.org/licenses/by/4.0/), which permits unrestricted use, distribution, and reproduction in any medium, provided the original work, first published in the Journal of Medical Internet Research, is properly cited. The complete bibliographic information, a link to the original publication on http://www.jmir.org/, as well as this copyright and license information must be included. 